\title{
Responses to cultural diversity in Botswana's schools: links between national policy, school actions and students' civic equality
}

\section{Citation}

Mulimbi, Bethany, and Sarah Dryden-Peterson. 2017. Responses to Cultural Diversity in Botswana's Schools: Links Between National Policy, School Actions and Students' Civic Equality. Journal of Curriculum Studies (November 6): 1-23.

\section{Published Version}

doi:10.1080/00220272.2017.1398353

\section{Permanent link}

http://nrs.harvard.edu/urn-3:HUL.InstRepos:34692517

\section{Terms of Use}

This article was downloaded from Harvard University's DASH repository, and is made available under the terms and conditions applicable to Open Access Policy Articles, as set forth at http:// nrs.harvard.edu/urn-3:HUL.InstRepos:dash.current.terms-of-use\#OAP

\section{Share Your Story}

The Harvard community has made this article openly available.

Please share how this access benefits you. Submit a story.

\section{Accessibility}




\title{
Responses to Cultural Diversity in Botswana's Schools: Exploring the Links between National Policy, School Actions, and Students' Civic Equality
}

\author{
Bethany Mulimbi ${ }^{\mathrm{a}}$ \\ Sarah Dryden-Peterson ${ }^{\mathrm{b}}$ \\ ${ }^{\text {a }}$ Harvard Graduate School of Education and Botswana Educational Research Association \\ ${ }^{\mathrm{b}}$ Harvard Graduate School of Education \\ Corresponding Author: \\ Sarah Dryden-Peterson \\ Harvard Graduate School of Education \\ 6 Appian Way \\ Gutman Library 457 \\ Cambridge, MA 02138 USA \\ Tel: 617-495-8164/ 617-435-2344 \\ Email: sarah_dryden-peterson@gse.harvard.edu \\ @drydenpeterson
}

\section{Acknowledgements}

We express our thanks to members of the school communities where we carried out this research - students, teachers, administrators, and staff; to colleagues at the University of Botswana, especially Owen Pansiri and Lydia Nyati-Saleshando; to our research assistants, Moyagabo, Mosenodi, Bopelo, and Kelebogile; to Meira Levinsoa, Paola Uccelli, and the Mowana Lab at the Harvard Graduate School of Education for feedback on earlier drafts.

\section{Funding:}

The study was generously funded by a Fulbright fellowship from the U.S. Department of State; a Sinclair Kennedy Traveling Fellowship, Dissertation Completion Fellowship, Research Enabling Grant, and Harvard Academy Junior Faculty Development Grant from Harvard University; and the National Academy of Education/Spencer Foundation.

\section{Research Ethics}

All research drawn upon in this essay was approved by the Committee on the Use of Human Subjects at Harvard University and the Botswana Ministry of Education and Skills Development. All participants were aware of our roles as academic researchers and provided with an information sheet about the research, its potential risks and benefits, and their rights within the research; adults gave their written consent for participation and children gave their written assent.

Disclosure Statement

The authors hold no financial interest or benefit arising from the direct applications of this research. 


\section{Author Bios}

Bethany Mulimbi is a Postdoctoral Fellow with the Botswana Educational Research Association. Her research focuses on the interplay between how formal education systems, individual schools, and teachers address the needs of students of diverse cultural and linguistic backgrounds, particularly in Southern Africa. She holds an Ed.D. from the Harvard Graduate School of Education.

Sarah Dryden-Peterson leads a research program that focuses on the connections between education and community development, specifically the role that education plays in building peaceful and participatory societies. Her work is situated in conflict and post-conflict settings and with Diaspora communities. She is concerned with the interplay between local experiences of children, families, and teachers and the development and implementation of national and international policy. She is on the faculty at the Harvard Graduate School of Education. 


\title{
Responses to Cultural Diversity in Botswana's Schools: \\ Links between National Policy, School Actions, and Students' Civic Equality
}

\begin{abstract}
This article examines nation-state policies that have prioritized toleration of diversity over recognition through comparative case studies of three junior secondary schools in Botswana. Through data collected in observations, focus groups, interviews, and Participatory Action Research, we demonstrate how the schools, which varied in the ethnic composition of their students, teachers, and surrounding communities, responded differently to the reality of their multicultural student bodies. Two followed national policies closely, while the third crafted school level policies adapted to its student population, yet tightly constricted by national policies and curriculum. In all three schools, students of ethnic minority backgrounds experienced varying degrees of shame, discrimination, and a sense of exclusion from the nation and found little recourse to discuss and address these experiences within the structures of their schools. We argue that schools could better develop students’ capacity for equal citizenship were they supported by national education policies and curriculum to recognize the cultural, historical, and linguistic diversity of Botswana’s ethnic minorities explicitly in schools.
\end{abstract}

\section{Keywords:}

curriculum, multiculturalism, civic equality, Botswana 


\section{Responses to Cultural Diversity in Botswana's Schools:}

\section{Links between National Policy, School Actions, and Students’ Civic Equality}

Unity: Botswana believes in the social harmony of all the different groups of people living in the country. Every person who is a citizen of Botswana irrespective of their colour or status in society is regarded as an equal to all.... Botswana encourages its people to be a united and proud nation (Tsayang, Rampha, \& Mpitse, 2009, p. 177).

This passage describes a national principle, unity, to students in Botswana's first year of secondary school, as part of the civics unit in their social studies class. This principle of unity has shaped nation-making in Botswana since its Independence in 1966. In this article, we examine how education in Botswana enables and constrains the negotiation of unity in the presence of ethnic diversity. Like many other democratic nations (Gutmann, 2004), Botswana has actively pursued national unity by promoting equality among its citizens, in this case through a combination of distributive justice and assimilationist policies. Botswana has redistributed diamond wealth into public services, including schools, which socialize students into national citizens through a centralized curriculum (Dryden-Peterson \& Mulimbi, 2017; Marope, 1996; Tabulawa, 2009). Schools’ curriculum, in turn, promotes national unity through explicit teaching of liberal democratic ideals, including civic equality. At the same time, it promotes unity through assimilation to a national identity, the cultural components of which are built on the majority ethnic group’s practices, historical perspectives, and language (Authors, under review), a situation echoed in diverse nation-states (see, for example, Ho, 2016; Lappalainen \& Lahelma, 2016).

This study explores the development of students into equal citizens in Botswana by examining the interplay between Doyle’s (1992) levels of curriculum-making: national education policies and curriculum (institutional), school-level policies and structures (programmatic), and 
student interactions (school and classroom). We ask to what extent schools are able to develop their students' skills for equal citizenship - including skills to advocate for their own and others' treatment as civic equals -within the context of assimilationist and nationally centralized education policies and curriculum. Given the salience of ethnicity in Botswana, we define equal citizenship as treating one another as equals regardless of ethnic background.

We present case studies of three junior secondary schools in three different districts of Botswana that vary in the ethnic composition of their student bodies and surrounding communities. In all of these schools, we find that individuals of ethnic minority backgrounds experienced varying degrees of shame, discrimination, and a sense of exclusion from the nation. The three schools, through their management teams, responded differently to the reality of their multicultural student bodies, with two following national policies closely and one crafting school-level policies adapted to its student population. Despite differing implementations of national policy, however, students had little recourse to discuss and address their feelings and identities within the structures of their schools. Building on Gutmann’s $(1999,2004)$ discussion of recognition versus toleration, we argue that students' continuing experiences of discrimination and unequal relations in Botswana's assimilationist curriculum environment yields further evidence of the importance of publicly recognizing cultural, historical, and linguistic diversity, rather than tolerating such diversity only in private spaces. This case holds lessons for other countries seeking to building civic equality through their education systems.

\section{Background}

\section{Ethnicity in Botswana}

Approximately 30 different indigenous ethnic groups currently live in Botswana (NyatiSaleshando, 2011), making it a highly multicultural state. Following Gutmann (1999), we use 
multiculturalism to refer to a condition of society characterized by having many cultures and individuals who identify with these cultures interacting with one another. The cultures relevant to this study are long-resident groups ${ }^{1}$ which we refer to as ethnic groups, as is common in Botswana. Of these groups, Botswana's Constitution explicitly recognizes eight 'major tribes' who share the common language, Setswana, and who live mainly in the southeast of Botswana. As is customary in English, we refer to these groups as Tswana. Botswana's ethnic groups also include several non-Setswana-speaking groups who live throughout the country but are concentrated in the west and north. Each of these groups, other than the Khoi and San groups, speaks a single language, mutually unintelligible with Setswana but in the same Bantu language family. As is common practice in Botswana, the ethnic groups not listed in Botswana's Constitution are those we term minority, while those listed in the Constitution we term majority (Nyati-Ramahobo, 2006b; Pansiri, 2012; Republic of Botswana, 2000).

Minority groups in Botswana are extremely varied in their cultural backgrounds, historical migrations into modern-day Botswana, and political and economic standing. For example, the Kalanga - the largest minority group at around $11 \%$ of Botswana's population have lived in the northeast of modern-day Botswana for at least five centuries and are wellrepresented in civil service and professional fields (Selolwane, 2004). The pastoralist Herero who constitute about one percent of Botswana's population - have lived mainly in the northwest of present Botswana only since the mid-1800s, with the largest influx fleeing the German genocide against them in modern-day Namibia around 1900 (Gewald, 1999). The historically nomadic Khoi and San have lived in Southern Africa for millennia, and some subgroups in Botswana have sought recognition as indigenous peoples in highly contentious legal battles (Hitchcock, Sapignoli, \& Babchuk, 2011). Moreover, individuals’ and groups’ responses to their status as minorities differ, with some assimilating to majority Tswana language and practices out 
of a desire for upward mobility, others asserting their marginality and demanding group-level rights and compensation for negative discrimination, and still others denying the relevance of the terms majority and minority, rather demanding the same group-level rights for all (see, for example, Werbner, 2002).

Given some minority group members’ preference for concealing their background and assimilating, it is important to consider the particular salience of language as a characteristic that allows individuals to identify one another's ethnic background in Botswana’s schools. Botswana’s ethnic groups are not recognizable through visible characteristics, with the notable exception of some Khoi and San communities. In schools, students wear uniforms, learn a prescribed national curriculum, and eat the same meals provided by the school, such that the most common cultural markers of ethnicity, such as dress, historical understandings, folklore, music, dance, and cuisine, rarely become apparent in day-to-day interactions. In this context, the language that an individual speaks, or the accent that others can detect when he or she speaks Setswana, becomes the clearest marker of ethnic background. While Setswana and English are the only languages sanctioned for use in schools (Nyati-Saleshando, 2011), an individual's home language can be difficult to conceal; many individuals from minority backgrounds do not speak Setswana fluently, use regionally-specific vocabulary, or have a detectable accent.

\section{Policy and Curricular Responses to Multiculturalism}

Botswana is the longest continuously democratic state in Africa, having held free and fair elections every five years since independence from Great Britain in 1966 (Alexander \& Kaboyaakgosi, 2012). Recognizing the potential for interethnic conflict, as experienced by many neighboring Southern African countries, Botswana's leaders have taken a consistent approach to mitigating this risk by equalizing access to resources such as education and embracing civic 


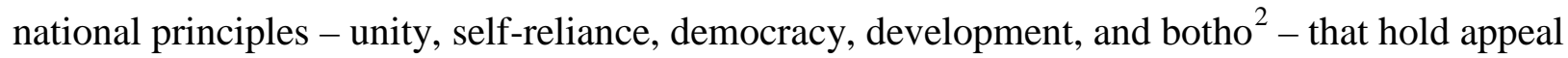
across ethnic groups (Dryden-Peterson \& Mulimbi, 2017; Gulbrandsen, 2012). Yet Botswana’s nation-building effort has been widely and increasingly criticized for its failure to recognize the many ethnic minorities within its borders, choosing instead to privilege the culture and language of the dominant Tswana ethnic groups (Gapa, 2017; Nyati-Ramahobo, 2006a; Tabulawa, 2009; Werbner, 2002). As early as 2000, a Presidential Inquiry into sections of the Constitution concluded that, due to widespread public perceptions of discrimination against minority ethnic groups: ' ...the long-term stability of this country, and in particular, the sustainability of its unity, could not be guaranteed' (Republic of Botswana, 2000, p. 9). As of this writing, the sections of the Constitution found to be discriminatory have remained unchanged.

Botswana has long recognized the potential for public schools to 'reinforce the aim of public unity’ (Republic of Botswana, 1977, p. 12) through curriculum and education policies. Creating near-universal access to schools has been a hallmark of Botswana's efforts to equalize resources for all citizens, and the vast majority of children today complete a ten-year basic education in government schools (UNESCO, 2011). Typically, there is a negative relationship between provision of public goods and ethnic diversity (see King, 2017 for a review of this literature), and thus Botswana is unique and notable in this redistribution of educational resources. Yet in its content, the current school curriculum promotes unity by emphasizing equality of citizens' rights and access to services while providing only limited recognition of uncontroversial aspects of multiculturalism, such as dress, music, and foods. It does not address more contentious aspects of multiculturalism that minority advocacy groups have brought to the media, courts, and political forums, such as divergent historical understandings, economic and political inequalities between ethnic groups, or language rights (Dryden-Peterson \& Mulimbi, 2017). In school curriculum, these more contentious aspects of minority culture and experiences 
are unrecognized and treated as private matters to be tolerated. Setswana remains the only indigenous language of instruction in schools, alongside English (Mhlauli, 2012; NyatiRamahobo, 2006b). We argue that Botswana's policy and curricular approach of promoting unity through assimilation to Tswana norms and language undermines schools' ability to build unity through equal citizenship.

\section{Conceptual Framework}

The value of civic equality holds that 'individuals should be treated and treat one another as equal citizens, regardless of their gender, race, ethnicity, or religion’ (Gutmann, 2004, p. 71). Civic equality is not only essential to most conceptions of democracy, but also necessary for strengthening national unity by demonstrating to diverse citizens their full inclusion in the nation-state (Banks, 2008; Gutmann, 2004; Kymlicka, 2015). In this section, we examine what theorists suggest schools should do in the interests of developing equal citizenship, specifically in response to multiculturalism, as well as challenges that schools and students will face if they fail to follow this approach (see Figure 1).

[Figure 1 about here]

Recognition and toleration are two potentially justifiable responses to multiculturalism within public schools, although the extent to which each response should be considered acceptable has been the object of considerable debate among political and educational philosophers (Gutmann, 2004; Sardoč, 2010; Taylor \& Gutmann, 1992). Recognition involves publicly acknowledging the contributions, perspectives, and experiences of groups, while toleration involves agreeing to disagree and privatizing differences (Gutmann, 1999). Botswana's policy and curricular approach has been for schools to promote the equal citizenship 
of individuals, by tolerating rather than recognizing the experiences and perspectives of minority ethnic groups.

Gutmann $(1999,2004)$ has argued compellingly that, to develop equal citizens, public schools must recognize the experiences and contributions of historically oppressed minority groups when not to do so would be 'disrespectful and discriminatory' (1999, p. 307). Disrespect and discrimination, in her argument, follow from the false assumption that because minority group experiences are absent from curriculum, they must not have contributed significantly to the nation. Gutmann further holds that individuals who identify with minority groups not only feel an important aspect of their social identity to be disrespected but also find it difficult 'to be empowered to share as civic equals in shaping their society' (1999, p. 306). From Gutmann's theory, we might expect that minority students whose cultures are not recognized in Botswana's schools would express feelings of shame or describe experiences of feeling disrespected or discriminated against based on their ethnic background (see, for example, Cook \& Sarkin, 2010; Gulbrandsen, 2012; Pansiri, 2012; Sekere, 2011). It follows then, that in order to prevent such experiences of shame and discrimination and promote civic equality between members of different ethnic groups, Botswana's schools need to recognize concerns that have been increasingly present in other public forums in Botswana: a) perceived inequalities between ethnic groups, b) not allowing minority languages in public schools, and c) historical and contemporary discriminatory interactions between ethnic groups (Dryden-Peterson \& Mulimbi, 2017).

Laden (2013) argues that equal citizenship requires that individuals act as equals, rather than simply believing that they are equal as a natural state. Central to acting as equals is relational justice, 'offering reasons to one another and evaluating the reasons others offer us' (Laden, 2013, p. 90), in cases where actions and decisions affect others in society. Equality, from a relational justice perspective, requires that those affected by decisions and policies find the 
reasons for those decisions and policies justifiable. It follows that schools must offer opportunities for students to develop their skills in offering and requesting reasonable justifications, such as by listening to the perspectives of others, attempting to understand their reasoning, and employing critical thinking in evaluating these perspectives and the impacts of these perspectives on others.

How can schools provide such opportunities for students and staff to have open conversations, particularly around controversial topics such as multiculturalism? Hess (2009) argues that in order to be able to discuss the topic openly, present different perspectives, and evaluate them in a school setting, the topic must be presented in curriculum or discussed in meetings or events in ways that show it is open for debate and discussion - that there is not only one acceptable response to the issue. In contrast, in the case of current social studies textbooks in Botswana, which acknowledge that minority groups speak a variety of languages, the choice of Setswana as the national language is treated as a closed issue, effectively impeding discussion around the value of using other languages in public spaces or as languages of instruction.

However, national curriculum and policies are not the only determinants of how a school may handle a controversial issue. Teachers and administrators may exercise what Levinson (2015) terms 'loyal subversion’ - ‘maintaining their loyalty to their students, school, and profession by subverting unjust policies, institutions, or structures whenever they think they can get away with it’ (p. 214). In Botswana’s public schools, such loyal subversion could, for example, consist of explaining material in minority languages to aid student comprehension, holding classroom- or school-level discussions about inequalities or discrimination between ethnic groups, or instituting policies meant to redress such inequalities. Laden (2013) suggests that in addition to modeling openness to questions and a willingness to give justifications in their own interactions, school staff can set aside times and structures for students to practice 
discussion and debate - such as through a student council, or debates in classes or clubs echoing findings of many empirical studies that suggest that these practices develop in situ, through experiences and relationships (see, for example, Llewellyn, Cook, \& Molina, 2010; Phillion, 2002).

Finally, the ways in which schools discuss or remain silent on multiculturalism affect schools' actions and students' experiences in relation to that multiculturalism. Writing about the development of language policies, Ruiz (1984) famously categorized discursive responses to minority languages in schools as 'problems,' 'rights,' or 'resources,' and argued that school language policies were curtailed by these discursive constructions. Pollock’s (2004) ethnography of the use of racial labels in one California school reminds us that choosing not to discuss controversial social categorizations - race in the United States, ethnicity in Botswana - does not make those categories less meaningful in schools or larger society. To address students’ needs that arise out of their diverse ethnic backgrounds requires acknowledging when and how ethnic identities are relevant in relation to school policies, interpretations of curricular content, or relationships within schools, rather than presuming ethnic identities to be irrelevant or addressed through one-size-fits-all equality discourse (Bryan, 2012; Teeger, 2015). Contemporary education policy and social studies curriculum in Botswana are largely silent on potential inequalities or differing perspectives between minority and majority ethnic groups. Here, we explore the way these policies and curricula are interpreted within schools, specifically whether and how individual schools in Botswana are similarly silent or develop school-level responses to their multicultural student bodies. 


\section{Methodology}

Through comparative case studies, we examine how public junior secondary schools in Botswana respond to their multicultural student populations and with what implications for students' development of equal citizenship across ethnic groups. We are particularly interested in how centralized national policies and curriculum play out in the practices of individual schools situated in varying regional and ethnic contexts. By attending to student experiences, we also examine whether students in these schools are developing skills and attitudes of equal citizenship. Through these analyses, we identify factors that enable and impede schools from promoting equal citizenship for students of different ethnic backgrounds.

We investigate the phenomenon of schools' responses to multiculturalism in different regions precisely because we are interested in how responses to multiculturalism might vary in schools situated within community contexts that differ in their ethnic composition. Our cases should be considered 'revelatory cases' (Yin, 2014, p. 52) because they illuminate a phenomenon - school-level responses to multiculturalism - in an underexplored regional and institutional context.

We expected the ethnic composition of the student body and surrounding community to influence schools' responses to multiculturalism, and thus chose school sites in three different regions of Botswana: Metsi School, in the Southeast, the most densely populated area of the country, predominantly Tswana (majority); Vula School, in the Northeast, the ancestral home of the Kalanga, the largest minority ethnic group in Botswana, whose leaders have actively sought language rights and cultural recognition; and Ami School, in the Northwest, a remote district, home to sizable populations of Wayeyi, Hambukushu, Herero, and KhoiSan, some of the smallest ethnic groups in Botswana. These sites include ethnic groups whose culture, languages, 
and historical perspectives are most recognized (southeast) and least recognized (northeast and northwest) in national education policies and curriculum. We further selected the schools to represent a range of characteristics typical of junior secondary schools in Botswana, in terms of size, rural/urban location, and boarding/day facilities (see Table 1).

[Table 1 about here]

Over six weeks at each school site between February-July 2015, we collected data on several sub-units and the interactions within and between them: school administrators, teachers and their individual classrooms, and students (see Figure 2). At each site, our sample included administrators with a variety of responsibilities (e.g. staff development and supervision, student guidance and support, liaising with families) and teachers from two core subject areas that have content most relevant to multicultural recognition: social studies and moral education (see Table 2).

[Figure 2 about here]

For lesson observations, staff interviews, and student focus groups and interviews, we focused on the middle year of junior secondary school, Form 2, in which students were aged 1417 years old. In the smaller schools, we collected data from all Form 2 classes (Metsi = 4 classes; Vula $=5$ classes $).$ In Ami School, which was much larger, we randomly selected four Form 2 classes from among the nine. After classroom observations and through conversations with teachers who knew the students well, we purposively sampled students to participate in focus groups of four to six students, seeking groups that were diverse in terms of sex, ethnicity, and observed classroom engagement level.

In the final two weeks at each school, we conducted semi-structured one-hour interviews with students who we deemed to be illustrative cases of themes emerging from the first month of data collection. Students were selected from among focus group participants, because their 
interaction with us in the earlier small group setting increased students' comfort level for being interviewed individually. Interviewed students again represented a range of sex, ethnic backgrounds, and school engagement levels. At each school, we continued interviewing students until we reached a point of data saturation and/or when we could not identify students from a relevant sub-group who were interested in being interviewed. We were not able to interview students from two sub-groups whose perspectives might have greatly enriched this analysis: KhoiSan students at Ami School and students from an area feeding into Metsi School that teachers and fellow students described as affected by extreme poverty and drug and alcohol abuse.

In all schools, we worked with a local research assistant who could translate between English and the dominant language(s) of that region. We conducted teacher interviews one-onone in English, without the translator. The translator and the first author co-led all student focus groups, with the translator asking all questions in the local language after the researcher asked them in English, and translating student responses when they were in the local language. Student interview participants chose whether to do the interview in English with the first author alone, in a combination of English and the local language with the first author and the translator, or in a local language with only the translator. We also relied on the translator or school staff to summarize the content of staff meetings, assemblies, PTA meetings, or other school events when local languages were used. After we completed data collection, we worked with a separate local research assistant to translate into English and transcribe from recordings all student interviews that were conducted in local languages.

[Table 2 about here]

We later returned to two of the schools to run participatory action research (PAR) clubs (see, among many, Cammarota \& Fine, 2008; Rodríguez \& Brown, 2009) with students over 
several weeks in August 2015 (Metsi School) and February 2016 (Ami School). ${ }^{3}$ In these clubs, we first presented preliminary findings from the initial phase of research and then worked with students to explore those findings they found most relevant and interesting through additional data collection. The clubs of nine to fifteen students (at Metsi and Ami, respectively) were open to any student who was in Form 2 during the 2015 school year. The student discussions during PAR clubs and student-led interviews with peers and community members yielded additional insights into issues of discrimination and disrespect for minority students. The PAR clubs also developed a survey and administered it to all students from their cohort in their schools. The researchers later administered the same survey on a return visit to Vula School in July 2016. Since the schools do not collect data on students' ethnic background, this survey provides the most comprehensive data available on the self-identified ethnic backgrounds of students in the three schools, and we use it here to provide a comprehensive view of self-reported ethnicity in each school.

These data collection strategies allowed us to examine how schools responded to their multicultural student bodies. In interviews with administrators, teachers, and students we asked specifically about the implementation of national policies (e.g. language policies and curricular content) at the school level. Through detailed fieldnotes, we also documented the implementation and adaptation of national policies and curriculum as observed across school contexts, such as in assemblies, school grounds, PTA meetings, and staff meetings, and as described in informal conversations. We compared data from the various contexts within each school and across the three schools to explore whether schools with higher proportions of minority students would develop school-level policies in response to the needs of their minority students and the responses of teachers and students. Interviews, focus groups, and informal conversations with students provided insight into the effects of school-level responses to multiculturalism on 
students' feelings in relation to their ethnic background, such as inclusion, shame, discrimination, pride. We triangulated across all data sources to identify those factors at each school that enabled or impeded schools from promoting equal citizenship between students of different ethnic backgrounds.

For our analysis, we worked from a uniform case study protocol for all schools (see online Appendix). After translating (where necessary) and transcribing all digitally-recorded focus groups and interviews and typing hand-written lesson observations and fieldnotes, we created a case study database using Atlas.ti. We aligned relevant codes for qualitative coding to each question from the case study protocol and thematically coded all data sources from each school. The protocol question 'What markers of ethnicity are relevant at this school,' for example, we aligned with the code family 'Signals of ethnicity,' which included among other codes 'food,' 'language,' ‘dress,' and 'phenotype.' From this thematic coding, we triangulated across data sources within each school to write an individual case report of each school, following the protocol questions. Finally, we examined each protocol question in turn across the three schools, comparing and contrasting the schools’ responses to their multicultural student bodies, in the process identifying school- and national-level factors that enabled or impeded schools’ development of equal citizenship in their students.

We checked the validity of our emerging findings through repeated and extensive discussion with others, including through conversations with our translators and school staff and students. Following data collection and a preliminary holistic analysis of all data sources from each school, we presented findings to students and/or teachers at each school and solicited their feedback through discussion. 


\section{Findings}

The three case study schools responded to their multicultural student populations with varying degrees of toleration and recognition. At Metsi and Vula Schools, students' ethnic diversity was unspeakable in public settings (assemblies, staff meetings, and lessons), whereas it was a more open topic of discussion in public settings at Ami School. Ami School was also the only school to implement policies designed to address effects of students' ethnic diversity, with Metsi School denying the relevance of multiculturalism and Vula School withdrawing from responsibility to address its effects. Regardless of the school-level responses to multiculturalism, however, students at all schools described experiences of disrespect and discrimination along ethnic lines at school and found little recourse within their schools to address these experiences.

\section{Talking about Multiculturalism}

While all three schools were multicultural - serving students from numerous different majority and minority ethnic groups - only Ami School publicly acknowledged this multiculturalism, in assemblies, staff meetings, and with student representatives. Because public schools in Botswana do not collect data on ethnic background, staff at all three schools based their assumptions of the student bodies' ethnic composition on their knowledge of the 'catchment area' - the communities that feed into the school. Ami School not only contained the most obvious ethnic diversity from its catchment area, but also recognized longstanding patterns of division between students of different ethnic groups and home languages at the school. The other schools' tendency not to discuss their students' multiculturalism rested on assumptions of cultural homogeneity and less notice of pressing student needs related to cultural diversity.

Metsi School is located in a majority Tswana area, situated in a major village of the Bakgatla (Tswana) group. Teachers and students alike frequently described the students' 
backgrounds in terms such as, 'we are in Kgatleng region. So most of us here are Bakgatla' (Focus Group 1). In reality, the student survey showed that only 52\% of respondents selfidentified as Bakgatla, with 12 other groups represented and 14\% of respondents coming from minority groups. However, based on the assumption of Bakgatla homogeneity, the school did not openly discuss students' ethnic backgrounds or consider how they may be relevant for students' experiences at the school. In the six weeks we spent at the school, the multiculturalism of the student body was never mentioned in public spaces (assemblies, lessons, staff meetings, or PTA meetings), nor did any respondent describe situations in which there was public discussion of the school's multiculturalism.

For an individual - student or teacher - to self-identify as a minority group member even in more private interactions (among friends, in a small group discussion, or private conversation) was rare. When we asked class teachers ${ }^{4}$ to identify ethnic minority students as we were selecting focus group participants, only one out of four teachers could identify a single student from a minority ethnic group (Fieldnotes March 2, 2015). During the focus groups, however, four students self-identified as members of minority groups. The three minority students whose class teachers did not know their ethnic backgrounds, moreover, surprised their peers when they disclosed their ethnic background in these groups. Students in the focus groups had already spent more than a year in class together and covered a 'cultural heritage' unit in their first-year social studies class. Among the exercises in this unit, students are asked to share practices from their ethnic group with their peers. When we asked why individuals at this school did not discuss their ethnic backgrounds, most teachers and students reported that there were too few non-Bakgatla students at the school to share knowledge of other groups (Focus Group 4; Interviews 4, 5, 11). However, in one-on-one interviews four out of six students said that students are ashamed to 
reveal their ethnicity for fear of being teased (Interviews 8, 10, 11, 12) (cf. Tabulawa, 2004, who finds that students had power to shape pedagogical practices in their schools).

Like Metsi School, members of Vula School tended to describe the school as mostly homogeneous, although in this case homogeneously Kalanga, Botswana’s largest minority ethnic group. The school is situated in the heart of the historical Kalanga homeland. While about $80 \%$ of students boarded at the school, most came from Kalanga villages near the school but too far to walk daily. The school had also been assigned by the Ministry of Education to receive KhoiSan students from a village about 200 kilometers away. Like Metsi School, we never heard public discussions of the school's multicultural composition. However, students and teachers in Vula School were well aware of each other's ethnic backgrounds, with the most important markers of ethnicity being ancestry (KhoiSan versus others) and home language (iKalanga ${ }^{5}$ versus Setswana). In interviews and focus groups, students openly discussed problems of bullying between KhoiSan and Kalanga students (Focus Group 10; Interviews 41, 43, 44, 46). Teachers and administrators described to us how KhoiSan students were failing exams and dropping out of school in large numbers (Interviews 34, 35, 40). Yet, however relevant these issues may have been for teachers and students, they were not discussed publicly at the school. Staff meetings were rare and dealt with exam scheduling and other logistics; they did not offer opportunities for teachers to raise emerging issues (Interview 39; Fieldnotes June 2, 2015). Students explained that they had told school officials about being bullied because of their ethnic groups, but the school officials did not address this in staff meetings or assemblies. Instead, they instructed the reporting students to ignore the bullies and treat one another equally, with no follow-up (Interviews 43, 44).

Like at Vula School, teachers and students at Ami School spoke often in private about the school's multiculturalism and problems that they saw arising from students' ethnic backgrounds. 
However, Ami School did not confine their acknowledgement of multiculturalism to these private conversations but discussed it openly in staff meetings and assemblies with the full student body. Located on the western side of the Okavango Delta, our survey revealed that half of the school's students are Wayeyi (a small ethnic group from the interior of the Delta), but there are sizable populations of Hambukushu (a border group with origins in Angola), Herero (a pastoralist border group with origins in Namibia), and KhoiSan (historically nomadic indigenous groups), in addition to a few students from each of a wide variety of other groups. The school has a very large catchment area, with some students boarding from villages over 100 kilometers west on gravel and sand roads. Many students choose not to board at the school, but instead live in the village on their own or with siblings, either because they are orphaned or their parents are caring for livestock on distant 'cattle posts.'

Staff and students at Ami School frequently raised two concerns about what they saw as problematic aspects of the school's multiculturalism: students' separating into language groups, and KhoiSan students' failing and leaving school. Staff and students discussed how KhoiSan and Herero, and to a lesser extent Hambukushu, students would group themselves during free time , such as during lunch or at the boarding hostels, and speak in their home languages. During our time at the school, administrators raised this concern in a staff meeting, teachers discussed the issue, and they agreed to encourage the students to break out of the same-language groups and integrate. The staff on duty then reiterated this point in a full-school assembly the same week (Fieldnotes May 5 \& 7, 2015). Students from the school's village, who usually speak Setswana at home, described how they would voice the same concern amongst themselves, as in the following case:

Some students group themselves by ethnic groups. If you join them you find them speaking a language that you don't understand and when you ask them to speak 
Setswana they refuse.... Mostly there are the Herero and [KhoiSan] who group themselves from others. (Interview 25, May 2015)

The public conversations about students' language grouping were dominated by teachers and Setswana-speaking students, who voiced only problematic perspectives on this issue. They decried the practice as ‘isolating,' ‘discriminating,’ or 'insulting’ (Focus Groups 6, 7, \& 8; Interviews 25, 27, May 2015; Fieldnotes May 5, 2015). They also linked it to students' difficulty achieving mastery of Setswana and English (Interviews 15, 22-24, May 2015), as when a Setswana-speaking student stated, ‘[A KhoiSan student in our class] doesn’t know Setswana very well, and he's not open. He’s just passive. He speaks to [KhoiSan students] only. And they speak in their language. So he struggles in English and Setswana, and they are taught in school' (Focus Group 7). Teachers similarly described KhoiSan students’ participation in school more generally in problematic terms during staff meetings, where they voiced frustration over these students’ poor academic achievement, reluctance to speak to others, and habit of running away from school to return home (Interviews 20, 22, 24).

While Ami School acknowledged its multicultural student population to a far greater extent than Metsi and Vula Schools, teachers described the existence and perceived enforcement of national policies as severely constricting the ways in which schools discussed multiculturalism. Formal curriculum does acknowledge the presence of many ethnic groups in Botswana but does not explain minority groups’ practices, discuss current or historical contentious relationships between ethnic groups, or acknowledge debates around language of instruction policies. In private conversations, interviews, or focus groups with us, the majority of teachers and students discussed knowledge of historical or current discrimination between ethnic groups that they had gained from discussions with family, media, reading non-curricular books, or everyday experiences in their communities. Yet we never observed a discussion of inequality 
or discrimination between ethnic groups in any lesson observation, meeting, or assembly in the three schools, marking a clear distinction between the kinds of conversations that happened in private spaces such as homes and interviews and those that took place in public spaces such as school lessons and meetings.

\section{Doing something about Multiculturalism}

Schools' actions in response to the multicultural nature of their student bodies corresponded to how they discussed or remained silent about their multiculturalism. Metsi and Vula Schools did not develop any school-level policies to address this multiculturalism, relying on national policies for language use, curriculum, and student life. Both schools promoted Setswana and English language of instruction policies, which stipulate that English be used in all subjects, except the Setswana language course, and across all school settings, with no public conversation connecting language policies to inequitable school outcomes for students. Vula School used the local iKalanga language in students' free time, on written memos for parents and community members, in parent teacher association (PTA) meetings, and even to provide additional explanations during lessons. The use of iKalanga, however, was not a formal policy, but more a widespread 'loyal subversion' (Levinson, 2015) of national policy by teachers from the region in response to the regional majority population (Fieldnotes June 1, 2015; Interviews 34, 35, 40, 51).

Taking their cue from formal curriculum in social studies, Setswana, and moral education classes, the schools promoted similarity and integration over difference and division among their students. Teachers highlighted to us and their students the importance of building unity by speaking Setswana as a common language, wearing the same uniform, eating the same food, and mixing students of different backgrounds in classes and boarding hostels (Interviews 1, 3, 5, 35, 41). At Metsi School, no teacher voiced concerns publicly or in interviews or informal conversations that these policies of uniformity were failing to promote their students' equal 
citizenship. At Vula School, on the other hand, every teacher we interviewed acknowledged that the school was struggling to meet the needs of its KhoiSan students, and that many of these students were struggling with a sense of inferiority compared to their peers. One KhoiSan student stated that she wished the school would call a meeting of all the students to discuss the poor relations between ethnic groups at the school and call for students to cooperate across ethnic lines, but that the school had taken no such actions (Interview 44). Faced with a dearth of national policies that would foster, or even allow, discussion of historical inequalities between ethnic groups at the school or address ongoing tensions between students from these groups, the school also did not develop school-level policies to support the needs of its multicultural student body. Rather, an administrator, frustrated that he had received no special preparation for receiving KhoiSan students, joyfully reported that he had convinced the Ministry of Education to stop sending these students to his school in future years (Interview 40).

Ami School presents a contrasting case. While it also promoted national approaches of integration and uniformity of the student body, school administrators supplemented these national policies with school-level practices meant to develop teachers' knowledge of the school's cultural context, redress inequities affecting KhoiSan students, and encourage students to cooperate across ethnic lines. The senior administrators driving these school-level approaches were from Northwest District, and they relied on their local knowledge and experience to develop relevant policies for their student body. However, these policies supplemented or reinterpreted national policies, rather than directly undermining them. The current national education policy, for example, places the responsibility of 'sensitizing teachers to cultural differences' with school administrators (Republic of Botswana, 1994, pp. 6, 16). Following this directive, the Ami School principal held an orientation for new teachers each year, in which, 
We orientate them about our students, orientate them about our environment, parents, and everything, even the locations... We talk about how the San look at things. We talk about the Hambukushu. We talk about the BaHerero. Because here we have a very large number of ethnic groups. So we talk, 'Oh no, this is how these people behave. This is how they interact.' (Interview 22)

While the national education system provides material resources to equalize KhoiSan and other rural students’ access to school, such as transport from their villages, boarding facilities, school uniforms, an allowance for school sports trips, Ami School took several additional actions to attempt to equalize KhoiSan students’ participation at school, a step toward realization of equal citizenship. The school instituted quotas for representation of different ethnic groups among class monitors, prefects, and student representative council members (Focus Group 6; Interviews 15, 20), brought a social worker from KhoiSan students’ home community and a KhoiSan teacher from a nearby school on separate occasions to try to motivate the students and understand their school experiences (Interview 24), and allowed students who had dropped out of school to re-enrol at any time during the year (Interviews 20, 22).

Ami School's policy of allowing students to re-enrol throughout the school year provides useful insights into the pressure school administrators face within the current national education policy environment. When the administrators instituted this flexible re-enrolment policy, they met with dissent from teachers, who cited a national policy allowing students who had left school for 20 days or more to re-enrol only at the start of a new school. A senior administrator insisted that he found the Ministry of Education flexible in allowing school administrators to craft school-level policies as long as they justified these policies to the regional education office: 'The Ministry actually can allow us to be flexible... You are empowered. But of course you will meet a lot of resistance from teachers' (Interview 22). One such teacher explained his resistance as stemming from the national policies that encouraged uniformity across all schools: 
I feel the purpose of our education system is for children to all be addressed equally, irrespective of their backgrounds... It is the very same government that said something of that nature. But we as teachers are instructed [by our school administration]... The way we treat other children from different cultures is supposed to be different from how we treat the [KhoiSan] children. (Interview 20)

Ami School's senior administrators' personal knowledge of the region and confidence in instituting policies in the face of teacher dissent allowed the school to respond with more recognition of its multicultural student population than Metsi and Vula Schools. Yet the policies only addressed student actions that the school openly discussed as problematic - in this case leaving school and isolating themselves from other students - rather than issues of inequality between ethnic groups that may have been driving these actions but were not open to public discussion in schools.

\section{Students' experiences of multiculturalism}

While the three schools responded to their multicultural student populations differently, similar student perceptions of and experiences with unequal inter-ethnic group relations indicated a need for deeper recognition of multiculturalism across all schools. Despite feeling that they learned in school the importance of treating all ethnic groups fairly, students brought up unanswered questions about the hierarchy of ethnic groups they perceived in their schools and communities: the eight constitutionally recognized Tswana groups were the most superior; the local majority culture was dominant over others in the school community; and those who were both constitutionally and numerically the minority they perceived to be the most inferior.

Students perceived some of these hierarchies as affecting them directly at schools and others being issues that they were more likely to face at the community or national level. In Metsi School, where the numerical majority was a Tswana group, minority students often masked their ethnic backgrounds and assimilated to the majority Bakgatla norms and dialect out of fear of being teased. At Vula School, where Kalanga students were the majority, students 
tended to describe how Kalanga were treated as inferior to Tswana in the country at large but not in their school. As one Kalanga girl said, 'Mostly in Botswana they consider ... all the ethnic groups that are in the south [Tswana groups], they take them as they are the most important [sic] than the ones that are from the Northeast [District]' (Interview 41). Students at Ami school similarly recognized that the Wayeyi were the largest ethnic group in their school and the village, and that this group faced discrimination outside of school but not within it. When we asked one Wayeyi student whether she felt her ethnic group was treated equally at school, she responded, Most people here in [Ami School] are Bayeyi, so there are small numbers of other people from different cultures. So mostly the Bayeyi tribe are the ones who don't treat others equally. They treat the [KhoiSan] unfairly and the Herero because of their language... They condemn their language and their lifestyle. (Interview 27)

Although, as this student noted, the Wayeyi often asserted their superiority at school through their better command of Setswana as compared to other minority ethnic groups, some Wayeyi students highlighted how their dialect of Setswana acted as a signal of their inferiority to Tswana groups. Discussing how the Wayeyi were treated by other groups outside of school, one boy stated, 'We in Northwest [District], we are discriminated from other parts because we usually speak this Setswana that is not perfect. They see us as people who belong to lower classes' (Interview 33). Individuals of minority ethnic backgrounds who spoke Setswana as their first language, such as many of the Wayeyi students at Ami School, still perceived that their inclusion as equal citizens of Botswana was undermined in relationships with their majority peers.

For students who identified with ethnic minority groups at the school and national level, particularly those who spoke minority languages at home, equal citizenship felt even less attainable. One student at Metsi School, who was one of only a few to proudly identify her Kalanga background in class, described how students responded by calling her Zimbabwean ${ }^{6}$ : 'Some people say that Kalanga people are not Kalanga, they're Zimbabwean... Most of the 
tribes [Tswana ethnic groups in Botswana], they come from South Africa. So they think that when they come from South Africa they're superior to these other tribes' (Interview 8). At Vula School, a student focus group that contained a mix of Kalanga and KhoiSan students discussed how they saw the KhoiSan as 'not recognized in the nation.' When we pressed for them to explain more, each of the students chimed in, saying that they felt this ethnic group is ignored and treated as though it does not exist, by the government and community members (Focus Group 10). In a one-on-one interview, one of the KhoiSan students reiterated this idea and described how it affected her at school, asserting, 'When we are [at Vula School] we are looked down [on]' (Interview 44). She went on to describe how other students and teachers would generalize to all KhoiSan students if a single one made a mistake in class, and how students at the boarding hostels would accuse KhoiSan students of isolating themselves from others if they sat and talked together. At Ami School, as described earlier, teachers and majority Wayeyi students similarly accused Herero, KhoiSan, and some Hambukushu students of 'isolating' themselves when they spoke their home languages in small groups during their free time. When members of these groups felt free to explain their perspective in one-on-one interviews, they described grouping themselves in order to learn about their ethnic groups' language, culture, and history. One Herero student stated, 'We as Herero like to speak our language. We like to promote history... We like to promote our culture' (Interview 33). She asserted that there was no other forum at Ami School than from each other in which Herero students could learn about their ethnic identity.

The student Participatory Action Research clubs provided evidence of the extent of discrimination and teasing along ethnic lines that was occurring in the schools. On the student surveys, students acknowledged that schools tried to promote equality through explicitly talking about it. The vast majority of students reported that 'teachers talk about equality' often or always 
(Metsi 75\%; Ami 73\%; Vula 72\%) and agreed or strongly agreed that 'At school I learn that it is important to treat all ethnic groups fairly’ (Metsi 86\%; Ami 92\%; Vula 93\%). However, in response to questions about the treatment of ethnic groups in schools, about half of respondents reported that their own ethnic group was 'treated unfairly at school' sometimes, often, or always (Metsi 48\%; Ami 43\%; Vula 50\%), and the majority responded that 'students at this school get teased about their ethnic group’ sometimes, often, or always (Ami 69\%, Vula 58\%). ${ }^{7}$ Students also responded that they believed it was a problem, a big problem, or a very big problem if such teasing was occurring in their schools (Ami 72\%; Vula School 80\%). A student research club participant in Ami School pointed out the disconnect he saw between what schools were explicitly saying about equality between ethnic groups and how students were not treating one another as civic equals: 'Teachers are always teaching us about tolerance and peace and how to promote it. I don’t think students should tease each other about their ethnic groups because we get the information from our teachers all the time' (Fieldnotes, February 11, 2016). Echoing research in other contexts, directives to treat each other equally, or to be anti-racist, do not foster conditions for equal citizenship (Bryan, 2012; Ho, 2016; Llewellyn et al., 2010; Teeger, 2015).

In focus groups, interviews, and especially the Participatory Action Research groups, students raised many concerns about unequal relations between ethnic groups in their schools and communities, yet none of the schools provided them with opportunities to address these concerns through open discussion and practice. In theory, the schools could have encouraged discussion through participatory structures such as the student representative council or structured classroom discussions and debates, even though formal school curriculum treats these topics as closed. While each school had an active Student Representative Council (student government) as well as class monitors and prefects who were responsible for reporting student 
concerns, we found no evidence of students discussing inequalities between ethnic groups through these structures.

One required school subject, moral education, provided an opportunity for students to practice skills necessary for relational justice (Laden, 2013) - to ask questions and offer justifiable explanations to others. Learning objectives in this class regularly asked students to debate the advantages and disadvantages of various decisions, and the course included an objective to 'analyse inequalities in Botswana.' Yet when we observed this objective being taught in Vula School, the students only discussed examples of inequalities mentioned in the textbook used in all three schools - those related to gender and disability. This text treated equality between ethnic groups as a closed issue, stating, 'everyone living in the country is protected by the law regardless of one's sex, race, ethnic group, or place of origin' (Fieldnotes June 11, 2015). In interviews, teachers also explained that on the rare occasion that students raised concerns about inequalities between ethnic groups in classes, teachers described it as a historical issue, rather than recognizing any of the continuing effects described by students. For example, one social studies teacher at Metsi School said, '[Students] are aware that in the past there were these eight major groups. And they are aware of these other minority groups. But I should think now they know that all people are equal in Botswana' (Interview 3). Like all other interviewed teachers, she said she teaches her students that all ethnic groups are equal today.

\section{Discussion}

As a longstanding democracy, Botswana has committed to promoting the equality of all its citizens, regardless of ethnic group, in the interests of establishing national unity. In the first 50 years after Botswana’s independence, education policy and curriculum have taken a distributive justice approach to promoting equality through equalized access to schools and uniformity - of 
language and understanding of the majority Tswana culture - alongside toleration of minority ethnic groups (Dryden-Peterson \& Mulimbi, 2017). Yet theorists have raised serious doubts as to the effectiveness of toleration alone for supporting students' development of civic equality treating one another as equals regardless of ethnic background (Banks, 2008; Brown, 2006; Gutmann, 1999, 2004; Kymlicka, 2015; Laden, 2013). The limited responsiveness of our three case study schools to their multicultural student bodies, and students' continuing experiences of discrimination and disrespect along ethnic lines, demonstrate the limitations of developing equal citizenship through Botswana’s current policies and curriculum.

All three schools worked within rather than subverting national education policies, and they represent a range of possible, acceptable school-level responses to multiculturalism in the present policy environment. Yet they do not create conditions for equal citizenship. From these schools' responses, we can identify policy- and curriculum- level factors that enable or impede schools' ability to develop students' equal citizenship. First, the Ministry of Education allows school heads to develop school-level policies that respond to the unique needs of their student body as long as they do not undermine national policies. Ami School's senior administrators capitalized on this flexibility to train their teachers in cultural norms of regional ethnic groups and encourage greater student participation in student leadership positions and through allowing re-enrolment after an extended absence from school. Yet their responsiveness to multiculturalism was not required by national policies and imposed additional burdens on the school's administrators, who had to develop school-level policies, convince the regional education office to allow them, and justify the policies to dissenting teachers. Under national policies, simpler and equally acceptable responses to the flexibility given to school heads were Metsi School's denial of the reality of multiculturalism among its students, and Vula School's choice not to develop school-level responses to address its effects. 
Second, school heads' jurisdiction to establish school-level responses to multiculturalism is extremely limited in its scope (see also, Adeyemi, 2009, pp., for discussion of centralized decision-making; Tabulawa, 2009). For example, despite high-level recommendations to teach minority languages in schools, language of instruction policies have remained rigid in their exclusive promotion of Setswana and English (Dryden-Peterson \& Mulimbi, 2017; NyatiSaleshando, 2011). Similarly, despite a national goal for public schools to 'recognise, support, and strengthen Botswana's wealth of different languages and cultural traditions' (Presidential Task Group for a Long-Term Vision for Botswana, 1997, p. 5), the formal curriculum in junior secondary schools provides only superficial recognition of uncontroversial aspects of multiculturalism, such as dress, music, and foods, and does not address more contentious issues such as alternative historical understandings, economic and political inequalities between ethnic groups, or language rights. The curriculum describes existing language policies and equality of ethnic groups as closed topics, not open to question or debate. Taking their lead from this curriculum, teachers and administrators did not invite discussion of these issues in any of the case study schools, although in private conversations many teachers and students revealed knowledge of, and concern about, these issues gained outside of school. Moreover, despite teachers' overwhelming awareness of the burden students faced under the national language of instruction policy, only Vula School very rarely used the local iKalanga language to aid student comprehension. Teachers' use of iKalanga there represented individual teachers' 'loyal subversion' of explicit school and national policies, not a school-level response to students' learning needs.

Schools' silence on controversial aspects of multiculturalism had tangible negative effects for their students. Students from unrecognized, minority ethnic groups in all case study schools described feelings of shame and embarrassment or treatment as inferior citizens, as 
compared to the eight recognized Tswana groups. Although many students revealed knowledge of and pride in their ethnic group when they were the numerical majority in their school, or when they associated with students of their same ethnicity, they had few opportunities to discuss their background openly in lessons or assemblies. They were also extremely reluctant to raise concerns about discrimination, disrespect, bullying, or feelings of exclusion based on their ethnicity in their classes or through student representative councils. Many students who spoke minority languages at home described struggling to gain proficiency in the two languages of instruction, Setswana and English, but heard no acknowledgment of this struggle from teachers. As schools maintained silence on the legal and political battles surrounding languages of instruction, within the school grounds students were accused of isolating themselves and discriminating against others when they spoke minority languages. Yet students who spoke these minority languages at school often did so out of a desire to maintain an integral aspect of their social identity. As Gutmann (1999) points out, schools' inability to respect some individuals' emotional need to identify with their ethnic group while respecting others' right to do so undermines civic equality (pp. 305-306).

Finally, education policies have established structures in junior secondary schools that support open student discussion of some issues relevant to their lives and provide opportunities for students to practice justifying responses to those issues. Students elect class monitors, prefects, and Student Representative Council members and then raise pertinent issues through these representatives. The required moral education class asks students to consider ethical dilemmas and identify advantages and disadvantages of various courses of action. Such structured opportunities for discussion, debate, and reasonable justification are necessary for relational justice, as Laden (2013) argues. Were controversial aspects of multiculturalism such as language policies, inequalities and disrespect between ethnic groups, and alternative historical 
perspectives to be treated as open topics in schools, students and teachers would already have structures through which to debate them and practice carrying out respectful and reasonable discussions.

\section{Conclusion}

There are two potential paths for educational policy and curriculum in Botswana to recognize the multiculturalism of student bodies and support students to develop the skills and practices to act as equal citizens regardless of ethnic group. The path available to schools at present requires that an individual school recognize the multicultural nature of its student body and relevance of ethnicity for students' experiences, and to put in place structures to address these realities despite national education policies and curriculum that equate equality with uniformity and downplay the relevance of ethnicity. A preferable path for Botswana's schools would account for students’ lived experiences in multicultural schools and prepare them to promote equal citizenship in society. In this path, schools would be supported by national education policies and curriculum to recognize that all schools are multicultural, acknowledge contemporary effects of historical inequalities, recognize the salience of multiple ethnic identities, and invite discussion of these issues, their effects, and how best to redress them.

In a country like Botswana, where education policies and curriculum are centrallydecided and implemented with fidelity at the school level , this latter path requires national policies and curriculum that embrace recognition of diverse ethnic groups both in rhetoric and expected practice. This recognition would acknowledge and explain diverse historical perspectives, ethnic identities, and cultural norms and accept the use of home languages in public spaces including schools, further allowing these languages to be offered as supplementary lessons where there are resources and requests from schools’ communities to do so. If these 
policies of recognition were in place at the national level, all schools in Botswana would be expected to implement them. Such policies of recognition would signal that the state views the topic of how best to ensure equal citizenship for members of all ethnic groups, in light of historical inequalities, as open for discussion and for action.

\section{Notes}

${ }^{1}$ This paper does not discuss recent immigrant groups, border groups, or religious and racial minority groups, whose needs and demands on the state warrant their own research and debate. For a discussion of the ethical grounds for group-differentiated claims, see Kymlicka (2009).

${ }^{2}$ Botho is roughly translated as 'humane behavior,' but is an all-encompassing moral code for how human beings should relate to one another through courtesy, respect, and compassion.

${ }^{3}$ Due to scheduling difficulties, Vula School declined our offer to conduct a PAR club with their students but welcomed a data sharing presentation for teachers and allowed students to complete the survey developed by the PAR clubs in the other two schools.

${ }^{4}$ Class teachers act as the main teacher responsible for a given class of students for the three years they spend at the school. As such, they tend to know the students in their class better than any other staff member at the school.

${ }^{5} i$ Kalanga is the language of the Kalanga ethnic group.

${ }^{6}$ Zimbabweans are looked down on in Botswana, because there is a perception that most are illegal immigrants who bring crime and violence.

${ }^{7}$ The survey questions about teasing based on students' ethnic groups were not included in the survey at Metsi School. After extended discussions with the research club participants at Metsi School about the pervasiveness of teasing, we agreed that these questions needed to be added to future surveys. However, $48 \%$ of students at Metsi responded on the survey that their own ethnic group was 'treated unfairly at school.' 


\section{References}

Adeyemi, M. B. (2009). The Challenges for Teachers in the Teaching of Topics Associated with Botswana's "Vision 2016". Multicultural Education, 16(3), 24-28.

Alexander, K., \& Kaboyaakgosi, G. (2012). A fine balance: Assessing the quality of governance in Botswana. Pretoria: Institute for Democracy in South Africa (IDASA).

Banks, J. A. (2008). Diversity, Group Identity, and Citizenship Education in a Global Age. Educational Researcher, 37(3), 129-139. doi:10.3102/0013189x08317501

Brown, W. (2006). Regulating aversion : tolerance in the age of identity and empire. Princeton, N.J.: Princeton University Press.

Bryan, A. (2012). 'You've got to teach people that racism is wrong and then they won't be racist': Curricular representations and young people's understandings of 'race' and racism. Journal of Curriculum Studies, 44(5), 599-629.

Cammarota, J., \& Fine, M. (2008). Revolutionizing education : youth participatory action research in motion. New York, NY: Routledge.

Cook, A., \& Sarkin, J. (2010). Is Botswana the miracle of Africa? Democracy, the rule of law, and human rights versus economic development.(Survey of Transnational Law). Transnational Law \& Contemporary Problems, 19(2), 453.

Doyle, W. (1992). Curriculum and pedagogy. In P. W. Jackson (Ed.), Handbook of research on curriculum (pp. 486-516). New York: Macmillan.

Dryden-Peterson, S., \& Mulimbi, B. (2017). Pathways Toward Peace? Negotiating National Unity and Ethnic Diversity through Education in Botswana. Comparative Education Review.

Gapa, A. (2017). Identity Management: The Creation of Resource Allocative Criteria in Botswana. African Studies Quarterly, 17(1), 1-22.

Gewald, J.-B. (1999). Herero heroes : a socio-political history of the Herero of Namibia, 18901923. Athens: Ohio University Press.

Gulbrandsen, Ø. (2012). The state and the social : state formation in Botswana and its precolonial and colonial genealogies. New York: Berghahn Books.

Gutmann, A. (1999). Democratic education. Princeton, N.J.: Princeton University Press.

Gutmann, A. (2004). Unity and Diversity in Democratic Multicultural Education: Creative and Destructive Tensions. In J. A. Banks (Ed.), Diversity and citizenship education : global perspectives (1st ed., pp. 71-96). San Francisco: Jossey-Bass.

Hess, D. E. (2009). Controversy in the classroom : the democratic power of discussion. New York: Routledge.

Hitchcock, R. K., Sapignoli, M., \& Babchuk, W. A. (2011). What about our rights? Settlements, subsistence and livelihood security among Central Kalahari San and Bakgalagadi. The International Journal of Human Rights, 15(1), 62-88. doi:10.1080/13642987.2011.529689

Ho, L.-C. (2016). 'Freedom can only exist in an ordered state': harmony and civic education in Singapore. Journal of Curriculum Studies, 49(4), 476-496.

King, E. (2017). International Development, Sustainable Development Goals and Pluralism. Toronto: Global Centre for Pluralism.

Kymlicka, W. (2015). Solidarity in diverse societies: beyond neoliberal multiculturalism and welfare chauvinism. CMS, 3(1), 1-19. doi:10.1186/s40878-015-0017-4

Laden, A. S. (2013). Learning to be equal: Just schools as schools of justice. In D. S. Allen \& R. Reich (Eds.), Education, justice, and democracy (pp. 85-111). Chicago: The University of Chicago Press. 
Lappalainen, S., \& Lahelma, E. (2016). Subtle discourses on equality in the Finnish curricula of upper secondary education: reflections of the imagined society. Journal of Curriculum Studies, 48(5), 650-670.

Levinson, M. (2015). Moral Injury and the Ethics of Educational Injustice. Harvard Educational Review, 85(2), 203-228.

Llewellyn, K. R., Cook, S. A., \& Molina, A. (2010). Civic learning: moving from the apolitical to the socially just. Journal of Curriculum Studies, 42(6), 791-812.

Marope, P. T. M. (1996). The impact of educational policy reforms on the distribution of educational outcomes in developing countries: The case of Botswana. International Journal of Educational Development, 16(2), 157-171. doi:10.1016/0738-0593(95)000399

Mhlauli, M. B. (2012). The paradox of teaching citizenship education in Botswana primary schools. European Journal of Educational Studies, 1(2).

Nyati-Ramahobo, L. (2006a). Language policy, cultural rights and the law in Botswana. Contributions to the Sociology of Language, 92(285-304).

Nyati-Ramahobo, L. (2006b). The long road to multilingual schools in Botswana. In O. Garcia, T. Skutnabb-Kangas, \& M. E. Torres-Guzman (Eds.), Imagining multilingual schools: Languages in education and glocalization (pp. 200-222). Tonawanda, NY: Multilingual Matters, Ltd.

Nyati-Saleshando, L. (2011). An Advocacy Project for Multicultural Education: The Case of the Shiyeyi Language in Botswana. International Review of Education, 57(5-6), 567-582.

Pansiri, N. O. (2012). Ethnocultural identities and school retention: The case of rural ethnic minorities in Botswana. AlterNative: An International Journal of Indigenous Peoples(8), 3.

Phillion, J. (2002). Classroom stories of multicultural teaching and learning. Journal of Curriculum Studies, 34(3), 281-300.

Pollock, M. (2004). Colormute: race talk dilemmas in an American school. Princeton: Princeton University Press.

Presidential Task Group for a Long-Term Vision for Botswana. (1997). Vision 2016: Long-Term Vision for Botswana, Towards Prosperity For all. Gaborone: Government Printing and Publishing Services.

Republic of Botswana. (1977). Education for kagisano: Report of the national commission on education. Gaborone: Government Printer.

Republic of Botswana. (1994). The Revised National Policy on Education. Gaborone: Republic of Botswana.

Republic of Botswana. (2000). Report of the Presidential Commission of Inquiry into Sections 77, 78, and 79 of the Constitution of Botswana. Gaborone: Government Printer.

Rodríguez, L. F., \& Brown, T. M. (2009). From voice to agency: Guiding principles for participatory action research with youth. New Directions for Youth Development, 2009(123), 19-34. doi:10.1002/yd.312

Ruiz, R. (1984). Orientations in language planning. NABE: The Journal for the National Association for Bilingual Education, 8(2), 15-34.

Sardoč, M. (2010). Toleration, Respect and Recognition: Some tensions. Educational Philosophy and Theory, 42(1), 6-8. doi:10.1111/j.1469-5812.2009.00546.x

Sekere, B. (2011). Secondary Education for San Students in Botswana: A New Xade Case Study. Diaspora, Indigenous, and Minority Education, 5(2), 76-87. 
Selolwane, O. (2004). Ethnic structure, inequality and governance of the public sector in Botswana. Retrieved from Geneva:

Tabulawa, R. (2004). Geography students as constructors of classroom knowledge and practice: a case study from Botswana. Journal of Curriculum Studies, 36(1), 53-73. doi:10.1080/0022027032000129532

Tabulawa, R. (2009). Education Reform in Botswana: Reflections on Policy Contradictions and Paradoxes. Comparative Education, 45(1), 87-107.

Taylor, C., \& Gutmann, A. (1992). Multiculturalism and "The politics of recognition" : an essay. Princeton, N.J.: Princeton University Press.

Teeger, C. (2015). "Both Sides of the Story": History Education in Post-Apartheid South Africa. American Sociological Review, 80(6), 1175-1200. doi:doi:10.1177/0003122415613078

Tsayang, G. T., Rampha, L., \& Mpitse, D. L. (2009). Social studies form 1: Learner's Book. Gaborone: Collegium.

UNESCO. (2011). Education for All Global Monitoring Report 2011: The hidden crisis: Armed conflict and education. Retrieved from Paris:

Werbner, R. (2002). Challenging minorities, difference and tribal citizenship in Botswana. Journal of Southern African Studies, 28(4), 671-684. doi:10.1080/0305707022000043467

Yin, R. K. (2014). Case study research : design and methods (Fifth edition. ed.). Los Angeles: SAGE. 


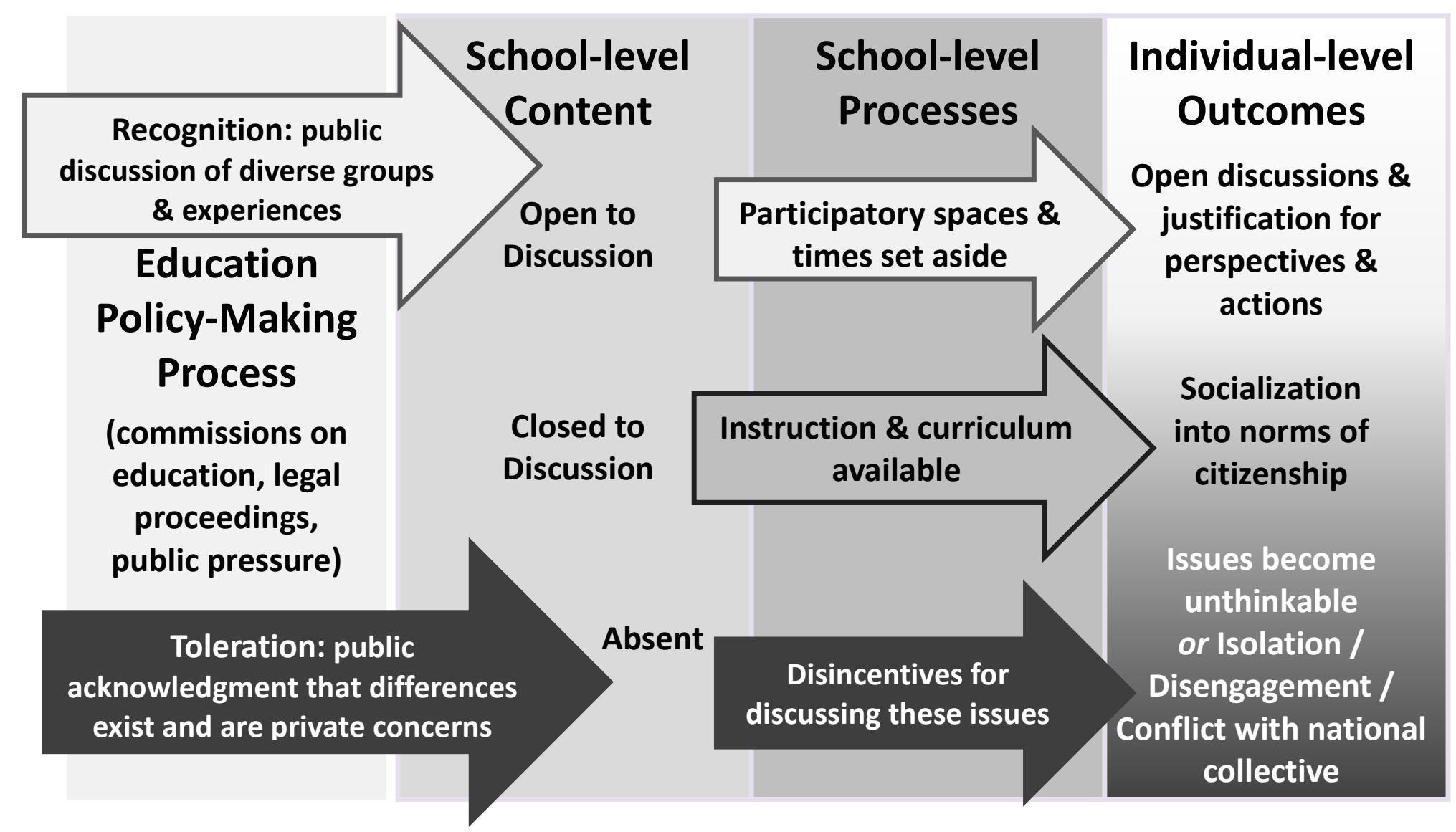

Figure 1. Connections between education policy approaches to cultural diversity, school-level content and processes, and individual student-level outcomes. 


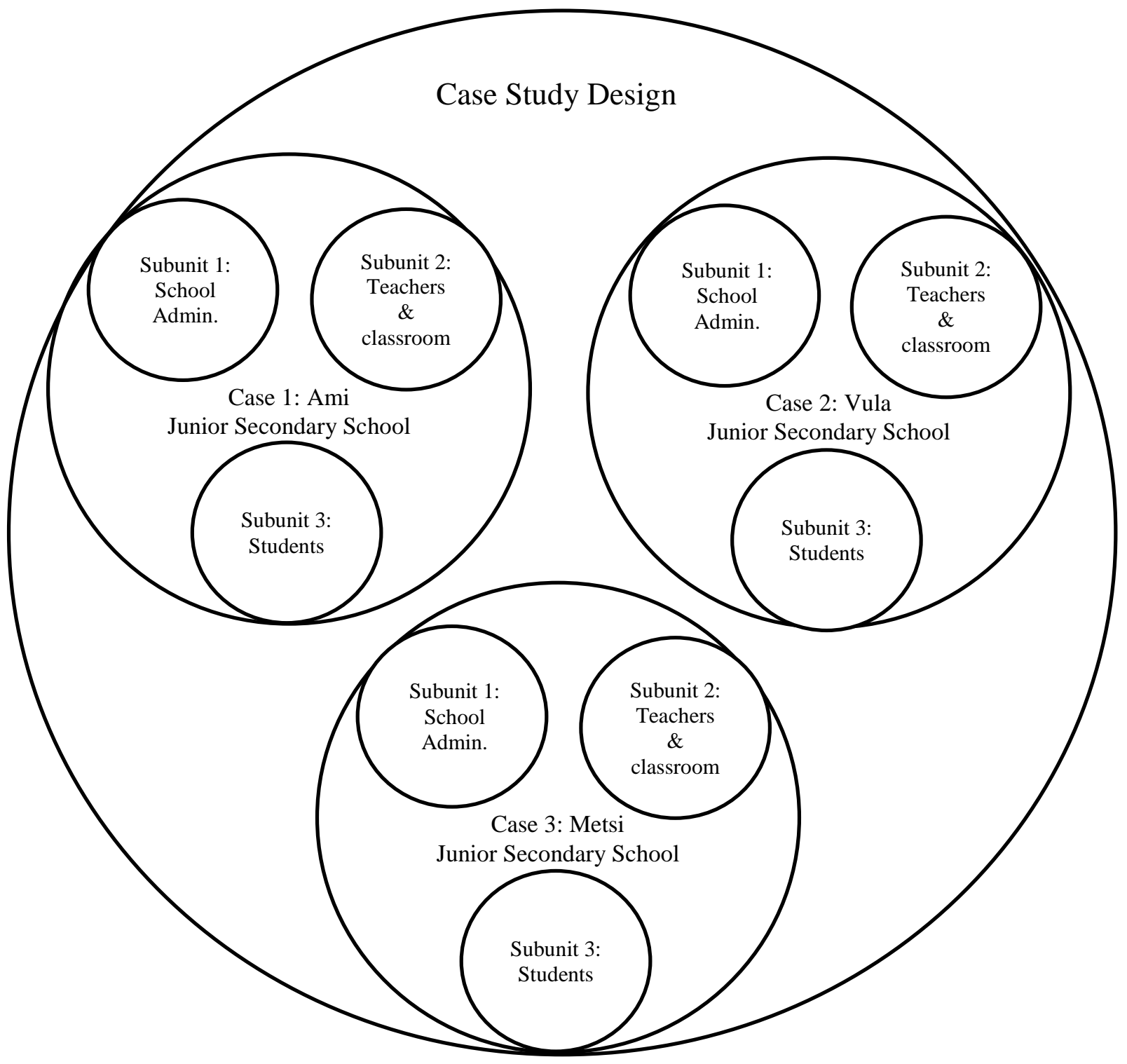

Figure 2. Multiple embedded case study design of junior secondary schools. 
Table 1

Characteristics of Case Study Schools

\begin{tabular}{lccc}
\hline School Name & Metsi School & Ami School & Vula School \\
\cline { 2 - 3 } Region & southeast & northwest & northeast \\
$\begin{array}{l}\text { Village size } \\
\text { Surrounding community ethnic composition } \\
\text { numerical } \\
\text { majority }\end{array}$ & small & small \\
$\begin{array}{l}\text { Bumgatla (Tswana) } \\
\text { minorities }\end{array}$ & Wayeyi & Kalanga \\
sizeable Herero & $\begin{array}{c}\text { Hambukushu, } \\
\text { various minorities }\end{array}$ & $\begin{array}{c}\text { few Herero, KhoiSan, } \\
\text { Tswana }\end{array}$ & Bangwato (Tswana)
\end{tabular}

\section{Student ethnic composition}

numerical

majority

Bakgatla (Tswana)

Wayeyi

Kalanga

numerical

wide variety,

very few

minorities
Hambukushu,
Herero, KhoiSan, few
Tswana
Bangwato (Tswana)
KhoiSan

\section{Staff ethnic composition}

regular teachers

mixed from across country, mostly Tswana and Kalanga

management

\begin{tabular}{lccc}
\multicolumn{1}{r}{ management } & $\begin{array}{c}\text { same as regular } \\
\text { teachers }\end{array}$ & $\begin{array}{c}\text { higher proportion } \\
\text { from northwest }\end{array}$ & $\begin{array}{c}\text { higher proportion of } \\
\text { Kalanga }\end{array}$ \\
\# students & $400-600$ & $800-1,000$ & $400-600$ \\
boarding & no & $<50 \%$ & $>50 \%$ \\
\hline
\end{tabular}

Note: Village sizes: small (0-15K), midsize (16K-50K), large (51K+) 
Table 2

Summary of Data Sources

\begin{tabular}{lccccccc} 
& $\begin{array}{c}\text { Field } \\
\text { notes }\end{array}$ & $\begin{array}{c}\text { Admin. } \\
\text { Interview }\end{array}$ & $\begin{array}{c}\text { Teacher } \\
\text { Interview }\end{array}$ & $\begin{array}{c}\text { Lesson } \\
\text { Obs. }\end{array}$ & $\begin{array}{c}\text { Student } \\
\text { focus } \\
\text { groups }\end{array}$ & $\begin{array}{c}\text { Student } \\
\text { Interview }\end{array}$ & $\begin{array}{c}\text { Student } \\
\text { Survey }\end{array}$ \\
\hline $\begin{array}{l}\text { Metsi } \\
\text { School }\end{array}$ & daily & $\mathrm{n}=1$ & $\mathrm{n}=6$ & $\mathrm{n}=12$ & $\begin{array}{c}4 \text { groups } \\
(\mathrm{n}=17)\end{array}$ & $\mathrm{n}=6$ & $\mathrm{n}=95$ \\
$\begin{array}{l}\text { Ami } \\
\text { School }\end{array}$ & daily & $\mathrm{n}=3$ & $\mathrm{n}=9$ & $\mathrm{n}=18$ & $\begin{array}{c}4 \text { groups } \\
(\mathrm{n}=19)\end{array}$ & $\mathrm{n}=9$ & $\mathrm{n}=174$ \\
$\begin{array}{l}\text { Vula } \\
\text { School }\end{array}$ & daily & $\mathrm{n}=1$ & $\mathrm{n}=6$ & $\mathrm{n}=14$ & $\begin{array}{c}5 \text { groups } \\
(\mathrm{n}=28)\end{array}$ & $\mathrm{n}=11$ & $\mathrm{n}=149$ \\
Total & 3 sets & $\mathrm{n}=5$ & $\mathrm{n}=21$ & $\mathrm{n}=44$ & $\begin{array}{c}13 \text { groups } \\
\text { (n=54) }\end{array}$ & $\mathrm{n}=26$ & $\mathrm{n}=418$ \\
\hline
\end{tabular}

Note: Most school administrators were unable to schedule a semi-structured interview at Metsi and Vula Schools, so their perspectives are captured in conversations recorded in fieldnotes. Fieldnotes covered a wide range of school activities and contexts (school assemblies, conversations on grounds, PTA and staff meetings, extracurricular activities, etc.) 